\title{
Memory Enhancing Efficacy of an Ayurvedic Polyherbal Formulation on Scopolamine-Induced Memory Deficit Experimental Models
}

\author{
Deepa Shukla $^{1,2}$, Sajal Srivastava ${ }^{2, *}$, Talha Jawaid ${ }^{3}$
}

\section{Deepa Shukla ${ }^{1,2}$, Sajal \\ Srivastava ${ }^{2, *}$, Talha Jawaid ${ }^{3}$}

'School of Pharmacy, Sharda University, Greater Noida, Uttar Pradesh, INDIA.

${ }^{2}$ Amity Institute of Pharmacy, Amity University Uttar Pradesh, Lucknow Campus, Lucknow- 226010, Uttar Pradesh, INDIA.

${ }^{3}$ Department of Pharmacology, College of Medicine, Al-Imam Mohammad Ibn Saud Islamic University, P.O. Box 11623, Riyadh 11544, SAUDI ARABIA

\section{Correspondence}

\section{Sajal Srivastava}

Amity Institute of Pharmacy, Amity

University Uttar Pradesh, Lucknow

Campus, Lucknow- 226010, Uttar Pradesh,

INDIA.

Phone no: 8808796867

E-mail: ssrivastava2@|ko.amity.edu

History

- Submission Date: 08-01-2020;

- Review completed: 12-02-2020;

- Accepted Date: 02-03-2020.

DOI : 10.5530/pj.2020.12.88

Article Available online

http://www.phcogj.com/v12/i3

Copyright

(C) 2020 Phcogj.Com. This is an open access article distributed under the terms of the Creative Commons Attribution 4.0 International license.

\begin{abstract}
The present study was performed to determine the efficacy of an ayurvedic polyherbal formulation (PHF) in the learning and memory process of animal models. The prepared PHF was a suspension of three plant extracts i.e. Alpinia galanga (AG), Glycyrrhiza glabra (GG) and Convolvulus pluricaulis (CP) along with other excipients. Learning and memory assessment of PHF was performed using different behavioral models in scopolamine-induced memory impairment animals. Biochemical estimation was performed to determine the enzymatic level of MDA, GSH and AChE level in rats. Results indicated that the time of social investigation trial 2 (SIT2) was reduced significantly compared to SIT1 due to the treatment of PHF. In the water maze test, plant extracts significantly decreased the latency time in the $4^{\text {th }}$ and $5^{\text {th }}$ sessions comparing to session 1. Administration of $A G, C P, G G$, and PHF caused amelioration of scopolamine-induced memory impairment in the MWM test. The extracts and PHF were also effective in reducing latency time in the pole climbing test. Biochemical parameters exhibited a reduction in MDA and AChE levels with an increase in GSH level after treatment with extracts and PHF. It can be concluded from the study that PHF is an effective formulation for learning and memory processes against scopolamine-induced memory impairment. Further, the isolation of active constituents is desired from different plant extracts.
\end{abstract}

Key words: Alpinia galanga, Glycyrrhiza glabra, Convolvulus pluricaulis, Pole climbing test Social recognition test, Latency time.

\section{INTRODUCTION}

Memory and learning are crucial mental processes occurring in the cerebrum of the brain. Memory is an important factor for all types of learning due to gathering and retrieving information after the learning process. $^{1}$ Learning and memory processes based on electrochemical signaling within the neuronal networks in the brain. ${ }^{2}$ Synaptic plasticity is a connection at the synapse of neurons that hypothetically to be modified during learning and memory disturbance. ${ }^{3}$ It is expected that modification of synapse function may lead to remodeling of neurons signaling as cognitive behavioral therapy. ${ }^{4}$ Cognitive behavioral therapy (CBT) helps in improving mental health by providing cognitive information and causing training-induced neuroplasticity. ${ }^{5}$

Medicinal Plants have been used since ancient times in the treatment of several disorders. ${ }^{6}$ Natural medicines are now attracting researchers in the development of several formulations due to low side effects and higher efficacy. ${ }^{7}$ The traditional medicines are used worldwide in the form of crude herbal extracts or herbal formulation in alleviating and curing nervous disorders. ${ }^{8}$ Alpinia galanga (L.) wild belongs to family Zingiberaceae, it is a well-known medicinal plant containing mild spicy fragrance, has been used in the Asian countries for treating various diseases and disorders such as diabetes mellitus, inflammation, oxidative stress, diarrhea, ulcer, stomach ache, spasm, and microbial and insecticidal infection. ${ }^{9-13}$ It is used as a nervine tonic in India. The plant of $A$. galanga is a class of the edible group and its rhizome possesses several active constituents in the form of essential oils such as p-hydroxycinnamaldehyde, galangin, galanganol $\mathrm{B}$, methyl cinnamate, trans-p-coumaric acid, alpinin, kampheride, and cincole. ${ }^{[14]}$

Glycyrrhiza glabra L. (liquorice) belongs to family Leguminosae. ${ }^{15,16} \mathrm{It}$ is an ayurvedic herb traditionally used in the treatment of insomnia and anxiety. ${ }^{17}$ It possesses several biological activities including neuroprotective, sedative-hypnotic, anticancer, immunomodulatory and hepatoprotective activities. ${ }^{18-20}$ This plant possess bioactive compounds such as glycyrrhizin, glycyrrhetinic acid, octadecane, octanoic acid and paeonol, benzaldehyde and 4-terpineol. ${ }^{21,22}$ It is a widely used food industry due to its sweet taste.

Convolvulus pluricaulis Linn. is a native plant of India belongs to family Convolvulaceae, it has been used traditionally as a memory enhancer and neuroprotective herb ${ }^{23,24}$ and in the treatment of several disorders such as liver diseases, diabetes, ulcer, anxiety, and oxidative stress. ${ }^{25-28}$ It is used as a tonic of the brain, reduces age-related degradation of neurons and also performs the anti-stress activity. ${ }^{29}$ The plant possessess numerous active constituents including shankhapushpine, scopoletin, and 29-oxodotriacontanol. ${ }^{30}$ 
Thus, due to wide utilization of selected folk medicines and phytotherapy as well, the protocol of the study was designed to evaluate the efficacy of these herbs in the form of polyherbal formulation (PHF) as brain tonic against Alzheimer's disease, mental problems and other brain disorders including Schizophrenia, and Autism. Biochemical analysis was performed to determine the level of acetylcholinesterase due to treatment with PHF.

\section{METHODOLOGY}

\section{Drugs and reagents}

Donepezil, Scopolamine, Propylparaben, Methylparaben, Tween 80 and Sodium carboxymethyl cellulose were procured from Sigma Aldrich, USA. All other solvents were of analytical grade and distilled water was used throughout the study.

\section{Preparation of polyherbal formulation (PHF)}

The prepared PHF containing $0.5014 \mathrm{~g}, 0.3343 \mathrm{~g}$ and $0.3343 \mathrm{~g}$ of Alpinia galanga (AG), Glycyrrhiza glabra (GG) and Convolvulus pleuricaulis (CP) extracts, respectively; further, the addition of parabens, tween 80 and a little amount of sodium carboxymethyl cellulose then uniformly triturated to form a smooth paste. The paste was rinsed with distilled water $(100 \mathrm{ml})$ and vortexed using a mechanical stirrer $(500 \mathrm{rpm})$ to get a suspension.

\section{Experimental design and drug administrations}

The effect of Alpinia galanga (AG), Glycyrrhiza glabra (GG) and Convolvulus pleuricaulis (CP) extracts and their PHF was evaluated inmemory impairment models induced by scopolamine.

\section{Scopolamine induced memory impairment}

Scopolamine was given on $5^{\text {th }}$ day to induce social recognition impairment. The memory function test was determined by using different experimental models such as Elevated plus maze, Morris water maze, Pole climbing test, and Social recognition test. Animals were divided into eleven different groups i.e. Group - 1 Control, Vehicle treated, orally (p.o); Group - 2 Toxic group, Scopolamine (i/p); Group - 3 Piracetam (200 mg/kg, i/p), Group - 4 AG1 extract $(100 \mathrm{mg} / \mathrm{kg}$, p.o), Group - 5 AG2 extract (200 mg/kg, p.o), Group - 6 GG1 extract (100 mg/kg, p.o), Group - 7 GG2 extract (200 mg/kg, p.o), Group - 8 CP1 extract (100 mg/kg, p.o), Group - 9 CP2 extract (200 mg/kg, p.o), Group - 10 PHF1 extract (100 mg/kg, p.o), Group - 11 PHF2 extract (200 mg/kg, p.o). Animals were administered for consecutive five days and memory function was evaluated from $5^{\text {th }}$ day onwards.

\section{Assessment of learning and memory}

\section{Social recognition test (SRT)}

Male adult rats weighing 225-250 g were used to evaluate the efficacy of PHF Scopolamine induced social recognition memory impairment. Scopolamine testing was performed in the cages on the $5^{\text {th }}$ day of drug administration in scopolamine $(1.25 \mathrm{mg} / \mathrm{kg})^{31}$ models. The social stimuli were generated using small rats weighing 50-60 g. The time interval of $5 \mathrm{~min}$ was recorded between adult rats and juvenile rats as social interaction between them (T1). The juvenile rats were removed from cages and re-introduced after $2 \mathrm{~h}$ to again record the social interaction time (T2).

\section{Morris water maze (MWM) test}

In this and afterward animal models, the highest dose of individual plant extracts and PHF i.e. $200 \mathrm{mg} / \mathrm{kg}$ was selected based on its efficacy in SRT. Male adult rats (225-250 g) were subjected to the Morris water maze (MWM) test from the $5^{\text {th }}$ day in the scopolamine model $(1 \mathrm{mg} /$ $\mathrm{kg}) .^{32}$ The water pool of $45 \mathrm{~cm}$ diameter and $26 \mathrm{~cm}$ height with four different starting points- N-E-SE-NW was used in this model. Animals were placed from anyone starting point of pool and any animal failed to escape from the pool within $120 \mathrm{~s}$ were placed at the side and allowed to stay for $30 \mathrm{~s}$. The index of learning was determined by escape latency time in the water maze.

\section{Pole climbing test (PCT)}

Pole climbing test was performed to evaluate the efficacy of PHF, it is an apparatus enclosed with a chamber $(25 \mathrm{~cm} \times 25 \mathrm{~cm} \times 40 \mathrm{~cm})$ with light and sound arrangement. This chamber containing a grid floor to provide electricity. The rat jump to the pole to avoid foot shock while delivering an electrical stimulus, it was recorded as escape and electricity were terminated, however, another response 'avoidance' was noted when jumping occurs due to the sound of the buzzer. The experiment was terminated after 10 trials with intervals of $30 \mathrm{~s}$. The animals were given the respective treatment and again subjected to the test procedure for 5 consecutive days after the completion of training. Reduction in escape latency time was considered as successful retention of avoidance memory. ${ }^{33}$

\section{Elevated plus maze (EPM) test}

Efficacy of PHF was studied on scopolamine-induced memory impairment using the EPM test. The apparatus containing open and closed arms in all four directions with a central platform. The height of the maze is approximately $25 \mathrm{~cm}$ from the floor. Animals were placed on the open arm and latency time was noted when the animal moves to a closed arm. latency time was assigned $90 \mathrm{~s}$ if one of the two arms was pushed gently. Examination of memory retention was done after a $24 \mathrm{~h}$ post-first-day trial. ${ }^{34}$

\section{Biochemical analysis}

\section{Evaluation of MDA level in scopolamine-induced amnesic rat brain}

Malondialdehyde (MDA) level was measured using a thiobarbituric acid reaction (TBAR) colorimetric assay. Briefly, TBA reagent was mixed with brain homogenate and were mixed in a test tube followed by incubation at $90^{\circ} \mathrm{C}$ for $60 \mathrm{~min}$. The test tube was then placed on ice cubes for cooling, it was centrifuged at $1000 \mathrm{RPM}$ for $10 \mathrm{~min}$. The supernatant was measured at $534 \mathrm{~nm}$ in a microplate reader. ${ }^{35}$

\section{Evaluation of GSH level in scopolamine-induced amnesic rat brain}

In this method, GSH was measured by preparing brain homogenate, it was precipitated in trichloroacetic acid in the concentration of $10 \%$ followed by centrifugation at $12,000 \mathrm{rpm}$ for $5 \mathrm{~min}$. The supernatant was incubated and absorbance was measured at $425 \mathrm{~nm}^{36}$

\section{Evaluation of AChE level in scopolamine-induced amnesic rat brain}

The acetylcholinesterase (AChE) level was measured as Ellman reagent $(100 \mu \mathrm{L})$ was filled in an individual well of 96 well plates. Brain homogenate $(10 \mu \mathrm{L})$ was added in each well containing Ellman reagent and the absorbance was measured at $456 \mathrm{~nm}$ in microplate reader followed by determination of protein content in brain homogenate. ${ }^{35}$

\section{RESULTS}

\section{Effect of PHF in SRT behavioral model}

Results exhibited that SIT2 was significantly decreased compared to SIT1. It indicated successful learning due to the administration of PHF. However, the scopolamine-induced group without treatment with test drug showed no change in the time during trial 2 comparing to trial 1. A significant reduction in SIT2 was noted in the piracetam $(200 \mathrm{mg} /$ 
$\mathrm{kg}$ ) administered group. Treatment with AG, CP and GG extracts at $200 \mathrm{mg} / \mathrm{kg}$ each have shown a significant reduction in SIT2 comparing to SIT1. It indicated the prevention of Scopolamine induced memory impairment (Figure 1). PHF was more effective than individual plant extracts in preventing scopolamine-induced memory impairment. Further, there was a significant difference in the recognition index of control, vehicle and Scopolamine group, confirming impairment of memory (Figure 2). The recognition index was significantly lower in piracetam, individual herbal extracts $(200 \mathrm{mg} / \mathrm{kg})$ and PHF $(200 \mathrm{mg} /$ $\mathrm{kg}$ ) treated groups.

\section{Effect of PHF in MWM behavioral model}

A significant decrease in latency time during the $4^{\text {th }}$ and $5^{\text {th }}$ sessions was observed in control $[\mathrm{F}(4,20)=7.0]$ and vehicle $[\mathrm{F}(4,20)=9.1]$ groups comparing to session 1 (Figure 3 ). The administration of scopolamine caused memory impairment throughout all water maze sessions. Treatment with piracetam caused a significant decrease $[\mathrm{F}(4,20)=6.5]$ in latency time during the $4^{\text {th }}$ and $5^{\text {th }}$ sessions in comparison to the first session. Plant extracts $(200 \mathrm{mg} / \mathrm{kg})$ caused amelioration of memory impairment in animals. Administration of AG $[\mathrm{F}(4,20)=9.5], \mathrm{CP}[\mathrm{F}$ $(4,20)=8.2]$ and GG $[\mathrm{F}(4,20)=7.1]$ extracts caused amelioration of scopolamine-induced memory impairment. No, any change was noted between the latency times of session 1 and session 2 of all groups (Figure 3). The PHF also significantly reduced $[\mathrm{F}(4,20)=6.9]$ latency from session 3 onwards in Scopolamine-induced memory deficit rats indicating successful learning of the MWM task.

\section{Effect of PHF in pole climbing behavioral model}

Control $[\mathrm{F}(4,20)=15.7]$ and vehicle $[\mathrm{F}(4,20)=9.4]$ groups exhibited significant reduction in the latency time on days $4^{\text {th }}$ and $5^{\text {th }}$, whereas, in the scopolamine group, no significant $[\mathrm{F}(4,20)=1.3]$ reduction was seen throughout all days. Administration of piracetam $200 \mathrm{mg} /$ $\mathrm{kg}$ caused significant $[\mathrm{F}(4,20)=8.5]$ reduction in the latency time from day 3 onwards indicating the prevention of scopolamine-induced memory impairment. Treatment with AG $[\mathrm{F}(4,20)=3.8], \mathrm{CP}[\mathrm{F}(4,20)$ $=5.2]$ and $\operatorname{GG}[\mathrm{F}(4,20)=4.9]$ extracts caused reduction of latency time on day 4 and 5. No, any change was noted between the latency times of day 1 of all groups (Figure 4). The PHF also significantly reduced [F (4,
$20)=10.5$ latency time from day 3 onwards in scopolamine-induced rats.

\section{Effect of PHF in EPM behavioral model}

The effects of plant extracts and PHF in the EPM test were evaluated on days $5^{\text {th }}$ and $6^{\text {th }}$. As shown in Figure 5, the transfer latency time in the retention trial was significantly lower than the acquisition trial in control and vehicle groups. However, the scopolamine group showed no significant change in retention latencies in comparison to the acquisition trial. Piracetam at $200 \mathrm{mg} / \mathrm{kg}$ significantly reduced latency time during retention trial in comparison to acquisition trial indicating the prevention of memory impairment. Treatment with AG, CP, and GG extracts caused amelioration of scopolamine-induced memory impairment as indicated by significantly lower latency time in retention trial (Figure 5). The PHF also significantly reduced latency time during the retention test in scopolamine-induced rats.

\section{Biochemical estimations}

\section{Effect of PHF on MDA level in scopolamine-induced amnesic rat brain}

The MDA level was raised significantly in the cortex and hippocampus of scopolamine-treated rats in comparison to the control and vehicle groups. Preventive treatment with piracetam significantly reduced MDA levels in both brain regions. Administration of $200 \mathrm{mg} / \mathrm{kg}$ of plant extracts significantly decreased MDA levels in the cortex and hippocampus of scopolamine-treated rats. PHF treatment also caused a significant decrease in MDA level in brain regions (Figure 6).

\section{Effect of PHF on GSH level in scopolamine-induced amnesic rat brain}

GSH level was observed using the calibration curve obtained with different concentrations of glutathione. Scopolamine caused a significant reduction in GSH levels in brain regions in comparison to control and vehicle groups. As shown in Figure 7, piracetam significantly prevented the scopolamine-induced reduction in GSH levels in the cortex and hippocampus. The administration of plant extract prevented the scopolamine-induced reduction in GSH levels. AG, CC, and GG

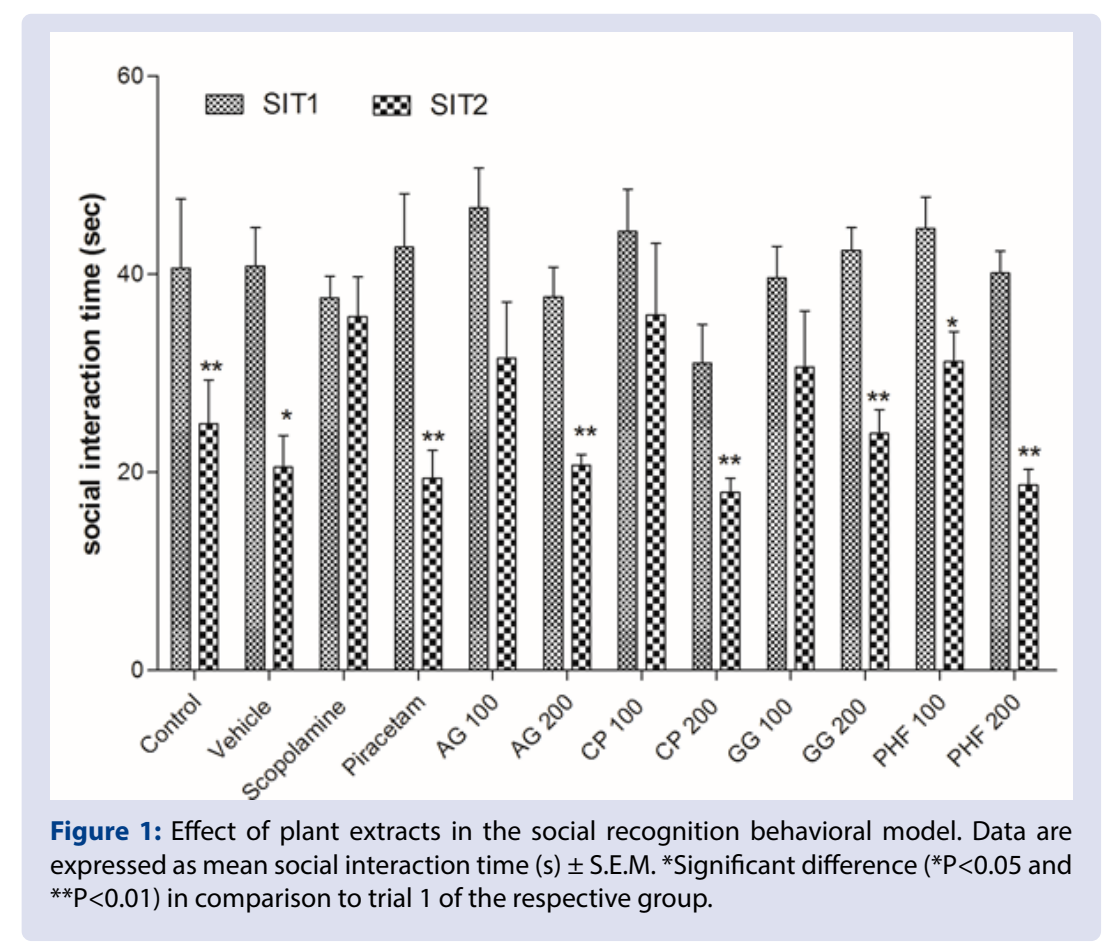




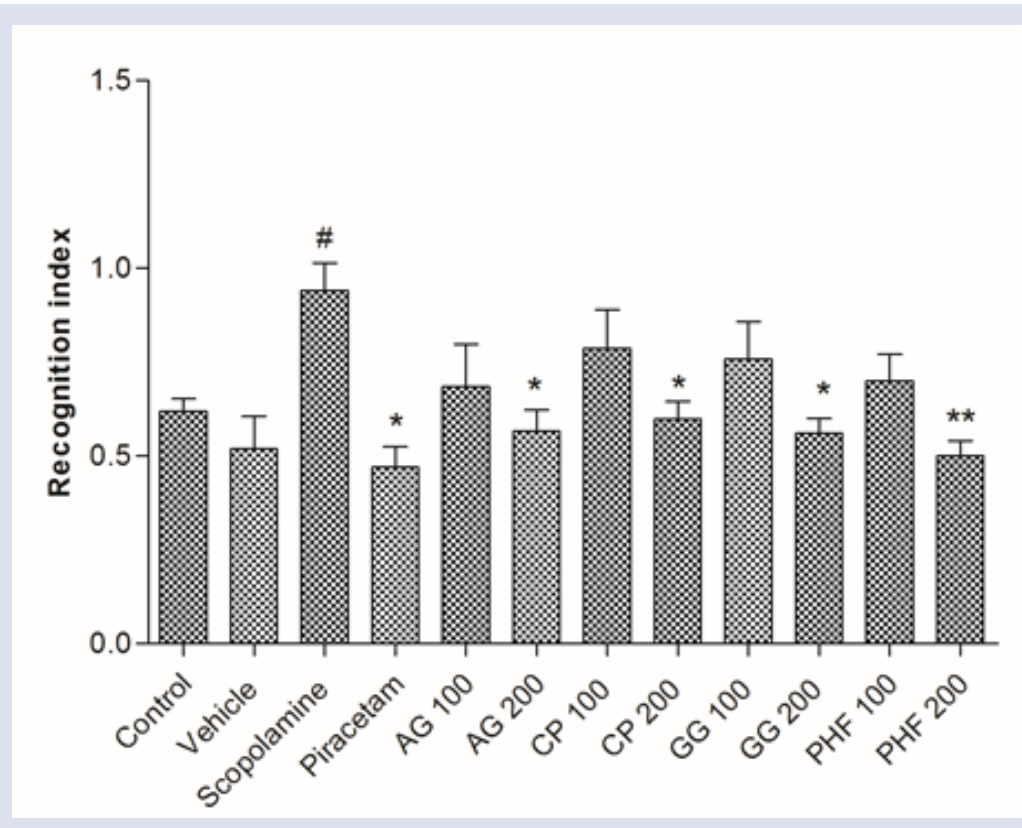

Figure 2: Effect of plant extracts social recognition test behavioral model. Data are expressed as mean recognition index \pm S.E.M. \#Significant difference $(\# P<0.05)$ in comparison to the control and vehicle groups and ${ }^{*}$ Significant difference $\left({ }^{*} \mathrm{P}<0.05\right)$ in comparison to the scopolamine group.

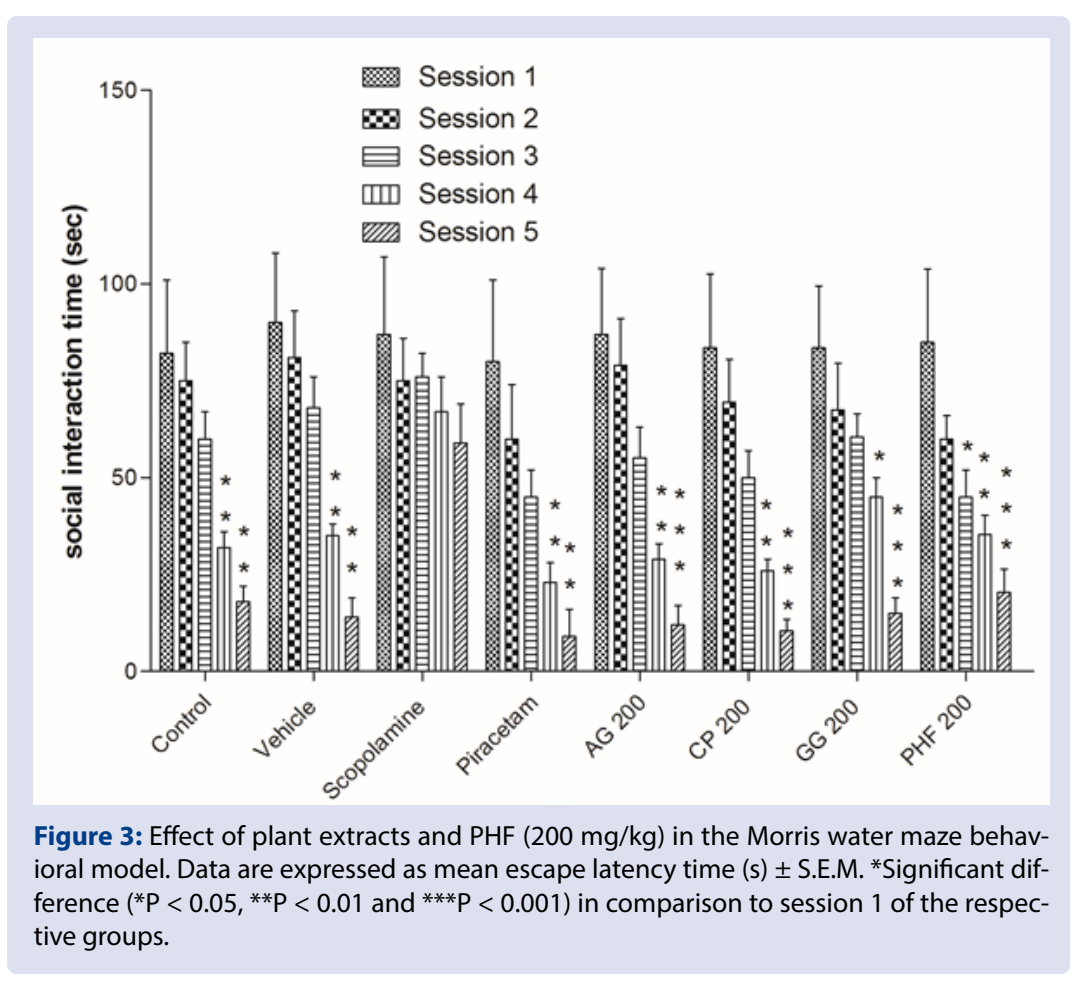

extract raised GSH levels in brain regions. PHF at $200 \mathrm{mg} / \mathrm{kg}$ also raised the level of GSH in brain regions (Figure 7).

\section{Effect of PHF on AChE level in scopolamine-induced amnesic rat brain}

AChE activity was raised significantly in brain regions in Scopolamine induced memory deficit rats. Preventive treatment with piracetam significantly inhibited AChE activity in brain regions (Figure 8). The administration of plant extract prevented scopolamine-induced elevation of AChE activity. AG, CC, and GG extract significantly decreased AChE activity in animals. PHF at $200 \mathrm{mg} / \mathrm{kg}$ also reduced
AChE activity in the brain regions (Figure 8)

\section{DISCUSSION}

Plants have been used in the development of the drug as an effective source of novel phytoconstituents in the treatment of several diseases. The phytotherapeutic approach has offered several opportunities to produce new drugs for memory disorders. ${ }^{37}$ In this study a polyherbal formulation (PHF) of three brain tonic herbs i.e. Alpinia galanga; Glycerrhiza glabra and Convolulus pluricaulis was evaluated against scopolamine-induced memory loss experimental models. In this cognitive-behavioral study, we found that this formulation was effective 


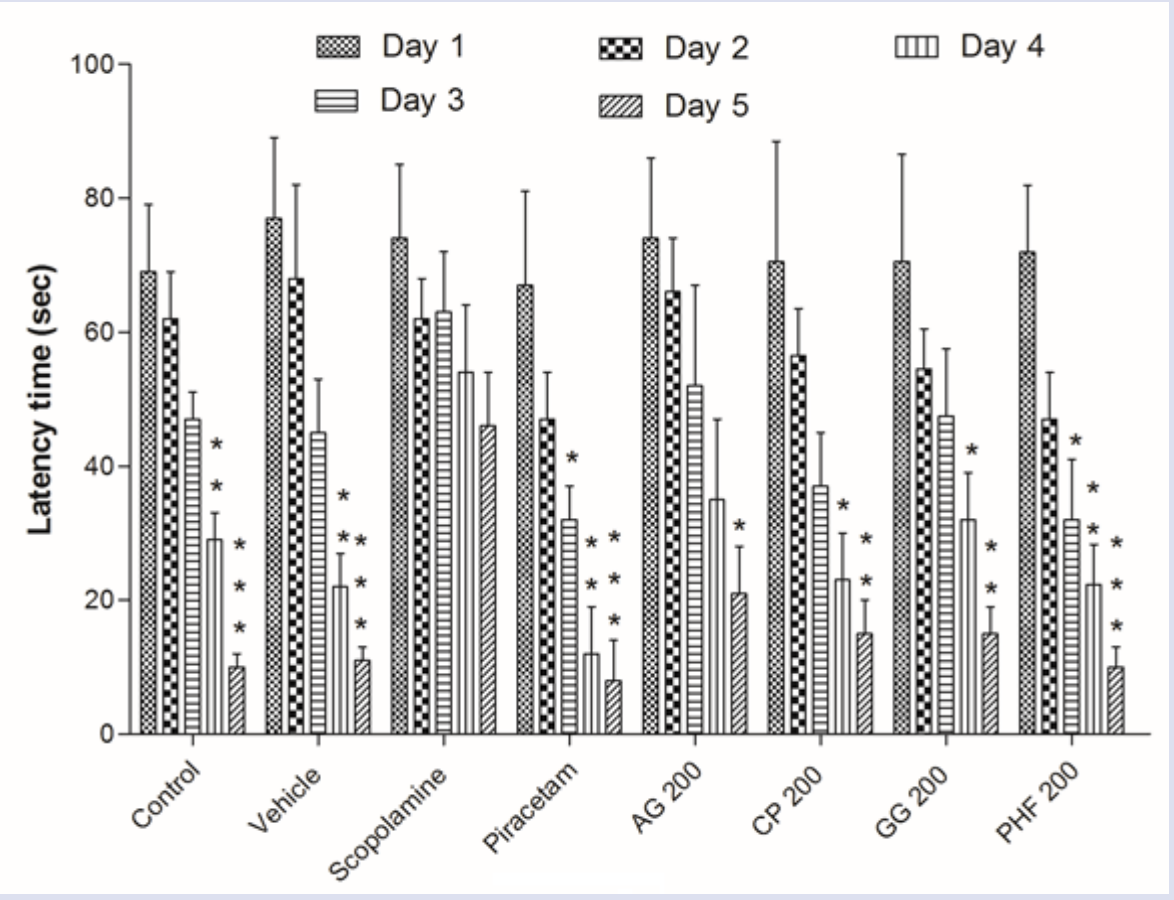

Figure 4: Effect of plant extracts and PHF ( $200 \mathrm{mg} / \mathrm{kg}$ ) in pole-climbing behavioral model. Data are expressed as mean latency time $(s) \pm$ S.E.M. ${ }^{*}$ Significant difference $\left({ }^{*} \mathrm{P}<0.05,{ }^{* * P}<0.01\right.$ and $\left.{ }^{* * * P}<0.001\right)$ in comparison to day 1 of the respective group.

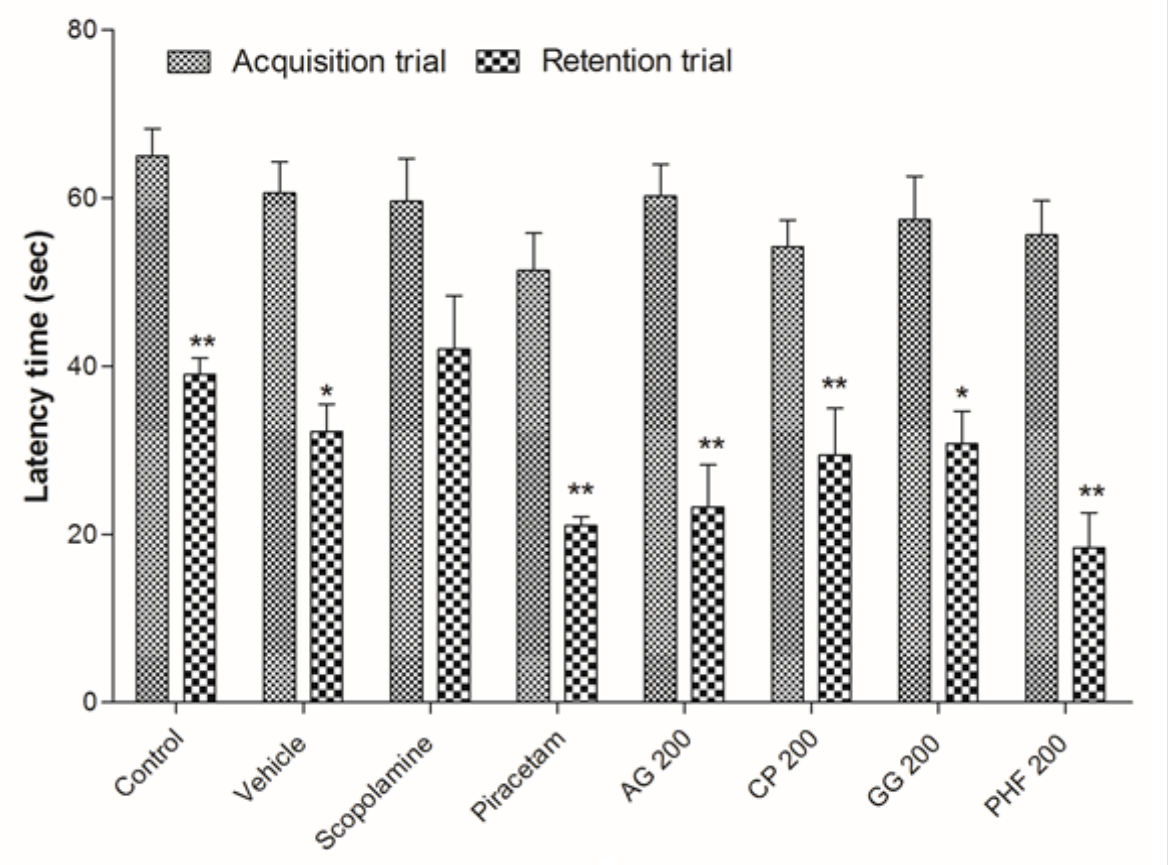

Figure 5: Effect of plant extracts and PHF ( $200 \mathrm{mg} / \mathrm{kg}$ ) in elevated plus maze behavioral model. Data are expressed as mean latency time $(s) \pm$ S.E.M. ${ }^{*}$ Significant difference $\left({ }^{*} P<0.05\right.$ and $\left.{ }^{* *} P<0.01\right)$ in comparison to the retention trial of the respective group. 


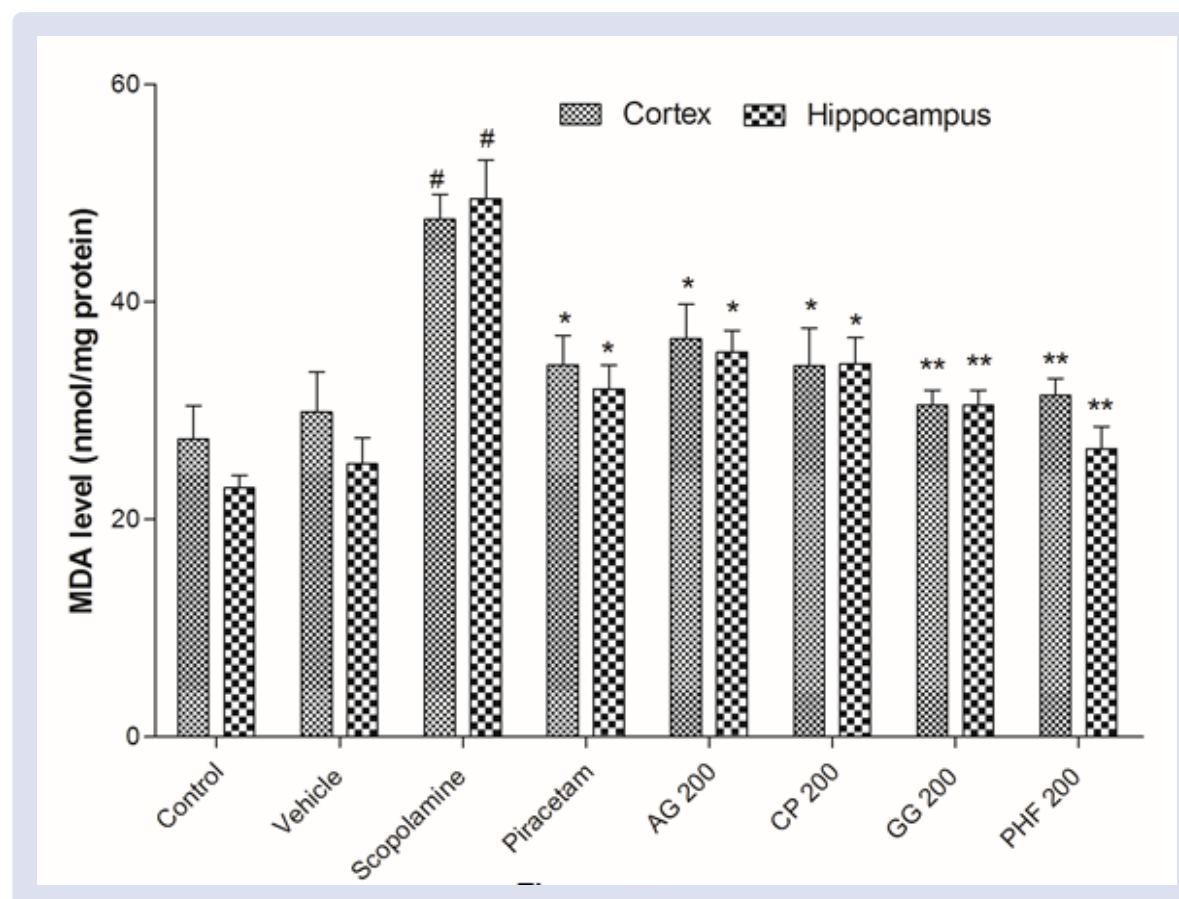

Figure 6: Effect of plant extracts and PHF ( $200 \mathrm{mg} / \mathrm{kg}$ ) on the malondialdehyde (MDA) levels. Data are expressed as mean MDA level ( $\mathrm{nmol} / \mathrm{mg}$ protein) \pm S.E.M. \#Significant increase $(\# P<0.05)$ in comparison to the control and vehicle groups. ${ }^{*}$ Significant increase $\left({ }^{*} P<0.05\right.$ and $\left.{ }^{* *} P<0.01\right)$ in comparison to the scopolamine group.

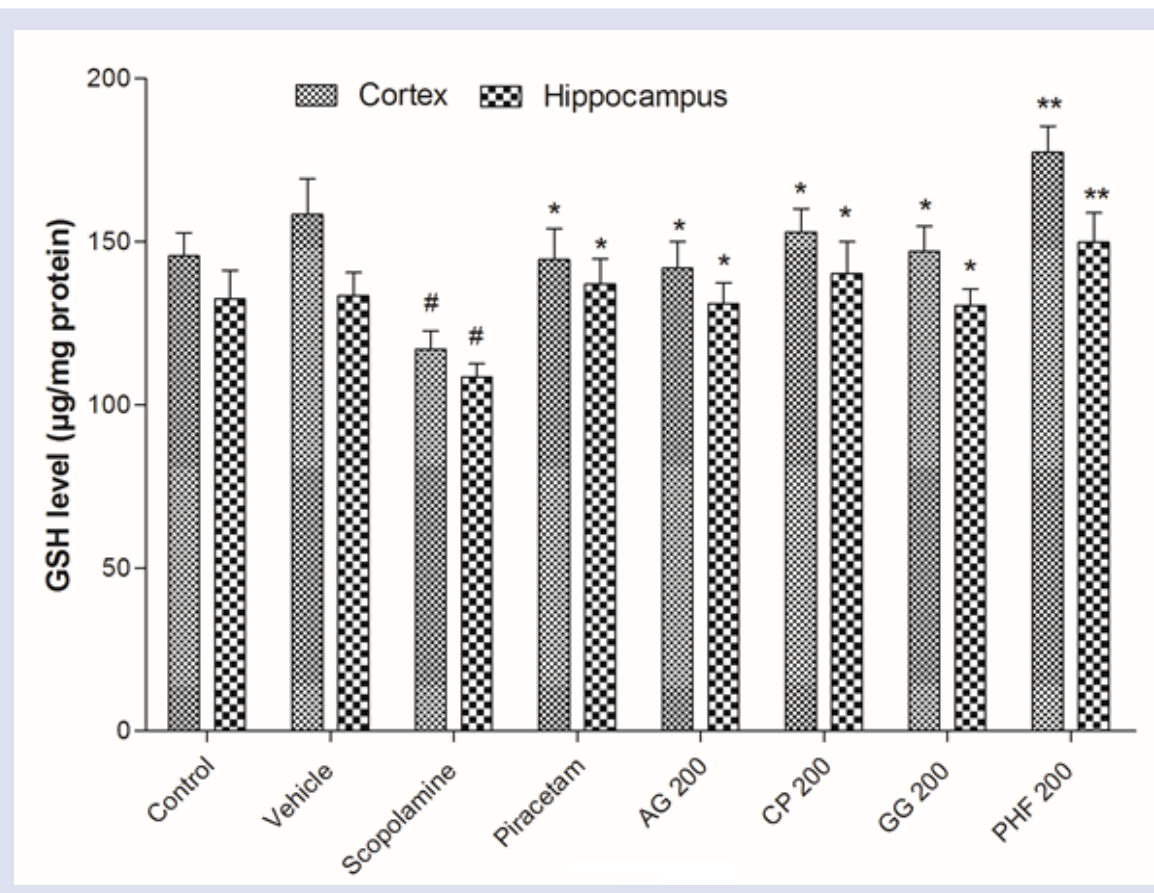

Figure 7: Effect of plant extracts and PHF (200 mg/kg) on the glutathione (GSH) levels. Data are expressed as mean GSH level ( $\mu \mathrm{g} / \mathrm{mg}$ protein) \pm S.E.M. \#Significant decrease $(\# P<0.05)$ in comparison to the control and vehicle groups. ${ }^{*}$ Significant increase $\left({ }^{*} \mathrm{P}<0.05\right.$ and $\left.{ }^{*} \mathrm{P} P<0.01\right)$ in comparison to the scopolamine group. 


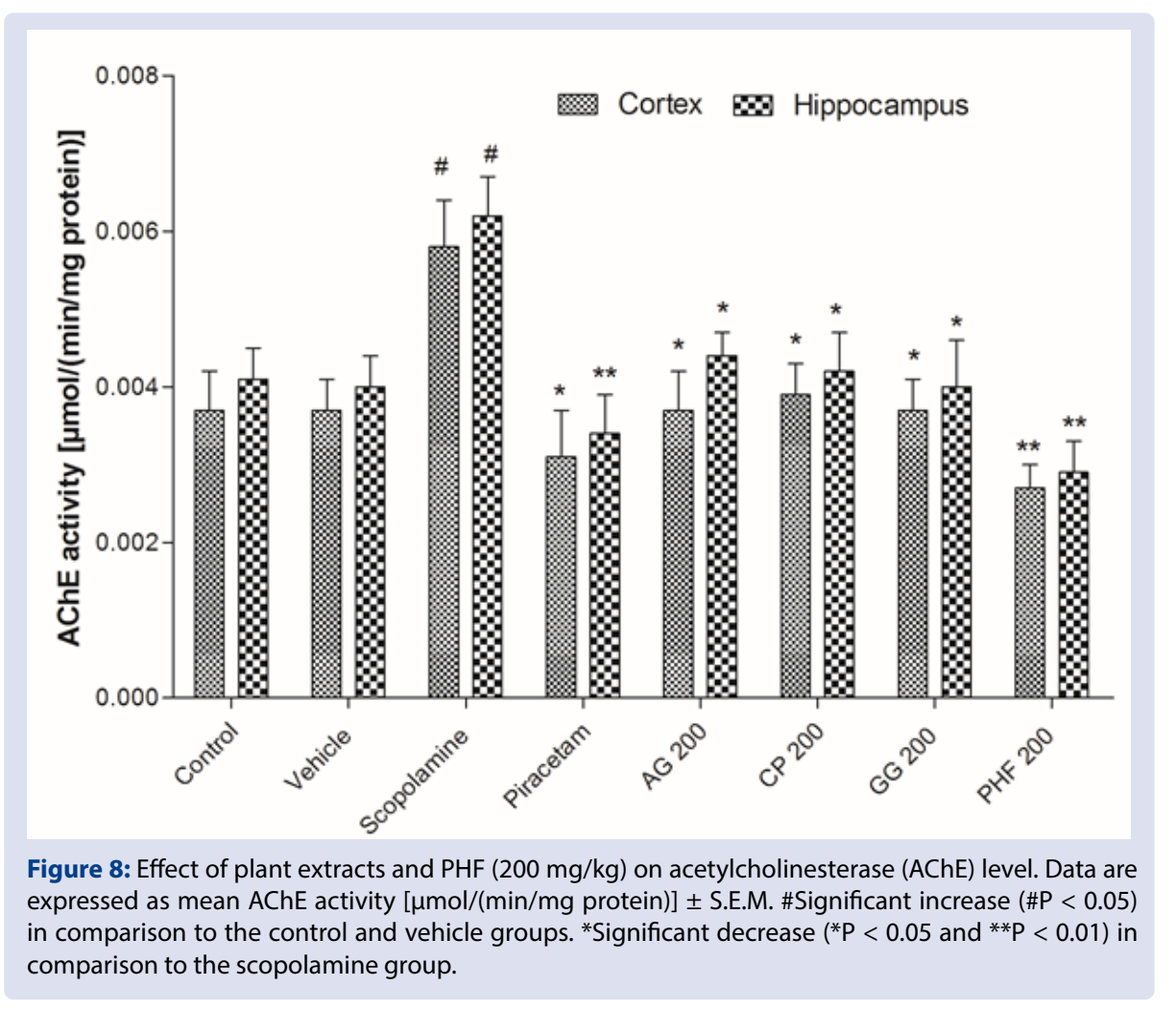

in the learning and memory process of different animal models. These medicinal herbs were selected due to their past India history of traditional uses as a memory enhancer and nervine tonic properties.

It has reported that Convolvulus pluricaulis has ameliorated neurotoxicity in the Drosophila model and depicted the neuroprotective herb. ${ }^{[30]} \mathrm{In}$ our study, PHF containing $\mathrm{CP}$ as one of the herbal drugs attenuated scopolamine-induced amnesia, it is supported by the work of Malik et $a l .^{38}$ As scopolamine impairs both short- and long-term memory processes in rodents and humans. ${ }^{39}$ Researchers also found that $\mathrm{CP}$ is an effective neuroprotective herb against the tumor, depression, epilepsy, anxiety and ulcer. ${ }^{7,23,27,40,41}$

Several behavioral studies have been used neuroprotective drugs against oxidative stress in the brain because the generation of free radicals indicates the progression of cognitive decline..$^{42}$ In this study, PHF reduced AChE activity in both regions of the brain in a dose-dependent manner. Hippocampus consolidates information from short-term to long-term memory and plays a role in forming, organizing and storing memories. ${ }^{43}$

\section{CONCLUSION}

It can be concluded from the study that PHF reduced scopolamineinduced amnesia via cholinergic function improvement, prevention of oxidative damage and behavior enhancement in the brain. Thus, PHF may be a potential candidate to prevent memory deficit in some neurodegenerative diseases.

\section{DECLARATION}

The author declares no conflict of interest.

\section{ACKNOWLEDGMENT}

The authors are thankful to the institute for providing all facilities required during the work.

\section{REFERENCES}

1. Abdul S, Adhikari N, Kotagiri S, Jha T, Ghosh B. European Journal of Medicinal Chemistry Histone deacetylase 3 inhibitors in learning and memory processes with special emphasis on benzamides. Eur J Med Chem. 2019;166:369-80.

2. Gotzsche CR, Woldbye DPD. Neuropeptides The role of NPY in learning and memory. YNPEP. 2016;55:79-89.

3. Reilly KC, Perica MI, Fenton AA. Synaptic plasticity/dysplasticity, process memory and item memory in rodent models of mental dysfunction. Schizophr Res. 2019;207:22-36.

4. Froemke RC, Carcea I, Barker AJ, Yuan K, Seybold BA, Martins AR, et al. Long term modification of cortical synapses improves sensory perception. Nat. Neurosci. 2013;16(1):79-88.

5. Voss P, Thomas ME, Cisneros-Franco JM, de Villers-Sidani E. Dynamic brains and the changing rules of neuroplasticity: implications for learning and recovery. Front. Psychol. 2017;8:1657.

6. Lewis HW, Elvin-Lewis MPH. Medical botany: plants affecting man's health New York: John.

7. Gupta GL. Protective effect of Convolvulus pluricaulis against neuroinflammation associated depressive behavior induced by chronic unpredictable mild stress in rat. Biomed Pharmacother. 2019;109(10):1698-708.

8. Mikawlrawng K, Rani R, Kumar S, Bhardwaj AR. Medicine Anti-paralytic medicinal plants e Review. J Tradit Chinese Med Sci. 2018;8(1):4-10.

9. Akhtar MS, Khan MA, Malik MT. Hypoglycaemic activity of Alpinia galangal rhizome and its extracts in rabbits. Fitoterapia. 2002;73:623-28.

10. Khattak S, Saeed-ur-Rehman, Shah HU, AhmadW, Ahmad M. Biological effects of indigenous medicinal plants Curcuma longa and Alpinia galanga. Fitoterapia. 2005;76(2):254-7.

11. Khumpirapang N, Chaichit $S$, Jiranusornkul S, Pikulkaew S, Müllertz A, Okonog S. In vivo anesthetic effect and mechanism of action of active compounds from Alpinia galanga oil on Cyprinus carpio (koi carp). Aquaculture. 2018;496(1):17684.

12. Tang $X, X u$ C, Yagiz $Y$, Simonne A, Marshall MR. Phytochemical profiles, and antimicrobial and antioxidant activities of greater galangal [A/pinia galanga (Linn.) Swartz.] flowers. Food Chem. 2018;255(8):300-8.

13. Zhao L, Chen LY, Liang JY. Two new phenylpropanoids isolated from the rhizomes of Alpinia galanga. Chin J Nat Med. 2012;10(5):370-3.

14. Satyavati GV, Raina MK, Sharma M. Indian council medical research. Delhi Cambridge Printing Works, 1976;46.

15. Gupta S, Riyaz-ul-hassan S. Community structure, spatial distribution, diversity and functional characterization of culturable endophytic fungi associated with Glycyrrhiza glabra L. Fungal Biol. 2019;123(5):373-83. 
16. Hoffmann KM, Beltran L, Ziemba PM, Hatt H, Gisselmann G. Potentiating effect of glabridin from Glycyrrhiza glabra on GABA A receptors. Biochem Biophys Reports. 2016;6:197-202.

17. Cho S, Park J, Pae AN, Han D, Kim D. Hypnotic effects and GABAergic mechanism of licorice (Glycyrrhiza glabra) ethanol extract and its major flavonoid constituent glabrol. Bioorganic Med Chem. 2012;20(11):3493-501.

18. Simmler C, Pauli GF, Chen S. Phytochemistry and biological properties of glabridin, Fitoterapia. 2013;90:160-84.

19. Yang R, Yuan BC, MaYS, Zhou S, LiuY. The anti-inflammatory activity of licorice, a widely used Chinese herb. Pharm Biol. 2017;55(1):5-18.

20. Iqbal I, Khanam R, Hassan S, Roou A, Moshahid Alam M, Islam A, Thakur S, Athara F. New insights into the antioxidant and apoptotic potential of Glycyrrhiza glabra L. during hydrogen peroxide mediated oxidative stress: An in vitro and in silico evaluation. Biomed Pharmacother. 2017;94:265-79.

21. Hayashi H, Sudo H. Economic importance of licorice. Plant Biotechnol. 2009;26:101-4.

22. Miyazawa M, Kameoka $\mathrm{H}$. Volatile flavour components of Glycyrrhizae radix (Glycyrrhiza glabra L. var. glandulifera Regel et Herder) from China. Flavour Fragrance J. 1990;5(3):157-60.

23. Sairam K, Rao CV, Goel RK. Effect of Convolvulus pluricaulis Chois on gastric ulceration and secretion in rats. Indian J Exp Biol. 2001;39(4):350-4.

24. Sethiya NK, Nahata A, Kumar P, Mishra SH. Neuropharmacological evaluation on four traditional herbs used as nervine tonic and commonly available as Shankhpushpi in India. J Ayurveda Integr Med. 2019;10(1):25-31

25. Ravichandra VD, Ramesh C, Sridhar KA. Hepatoprotective potentials of aqueous extract of Convolvulus pluricaulis against thioacetamide induced liver damage in rats. Biomed Aging Pathol. 2013;3(3):131-5.

26. Jai M, Maninder K, Karan V. Nootropic, anxiolytic and CNS-depressant studies on different plant sources of shankhpushpi. Pharm Biol. 2011;40(12):1234-42.

27. Nahata A, Patil UK, Dixit VK. Anxiolytic activity of Evolvulus alsinoides and Convulvulus pluricaulis in rodents. J Exp Biol. 2009;47(5):444-51.

28. Prasad SB, Sharma A. Antioxidant activity of Convolvus plauricalis. Invent Rapid Plant Act. 2011;79(11).

29. Anupama KP, Shilpa O, Antony A, Siddanna TK, Gurushankara HP. Convolvulus pluricaulis (Shankhapushpi) ameliorates human microtubule- associated protein tau (hMAP $\tau$ ) induced neurotoxicity in Alzheimer's disease Drosophila model. 2019;95(10):115-22

30. Rachitha P, Krupashree K, Jayashree GV, Kandikattu HK, Amruta N, Gopalan N, Rao MK, Khanum F. Chemical composition, antioxidant potential, macromolecule damage and neuroprotective activity of Convolvulus pluricaulis J Tradit Complement Med. 2018;8:483-96.

31. Loiseau F, Dekeyne A, Millan MJ. Pro-cognitive effects of 5-HT6 receptor antagonists in the social recognition procedure in rats: implication of the frontal cortex. Psychopharmacology (Berl). 2008;196:93-104.

32. Jawaid T, Jahan S, Kamal M. A comparative study of neuroprotective effect of angiotensin converting enzyme inhibitors against scopolamine-induced memory impairments in rats. J Adv Pharm Technol Res. 2015;6:130-5.

33. Goverdhan P, Sravanthi A, Mamatha T. Neuroprotective effects of meloxicam and selegiline in scopolamine-induced cognitive impairment and oxidative stress. Int J Alzheimers Dis. 2012:407-16.

34. Kulkarni SK, Singh K, Bishnoi M. Elevated zero maze: a paradigm to evaluate antianxiety effects of drugs. Methods Find. Exp Clin Pharmacol. 2007;29:343-8.

35. Rahimzadegan M, Soodi M. Comparison of memory impairment and oxidative stress following single or repeated doses administration of scopolamine in rat hippocampus. Basic and Chemical Neuroscience. 2018;9(1):5-14.

36. Nigam A, Kulshreshtha M, Panjwani D. Pharmacological evaluation of Hibiscus abelmoschus against scopolamine-induced amnesia and cognitive impairment in mice. Adv Hum Biol. 2019;9:116-23.

37. Elisa T, Paula A, Laiz P. Taraxerol as a possible therapeutic agent on memory impairments and Alzheimer's disease: Effects against scopolamine and streptozotocin-induced cognitive dysfunctions. Steroids. 2018;132(1):5-11.

38. Malik J, Karan M, Vasisht K. Attenuating effect of bioactive coumarins from Convolvulus pluricaulis on scopolamine-induced amnesia in mice. Nat Prod Res. 2016;30:578-82.

39. Bubser M, Byun N, Wood MR, Jones CK. Muscarinic receptor pharmacology and circuitry for the modulation of cognition. Handb Exp Pharmacol. 2012;208:121-66

40. Verma S, Sinha R, Kumar P, Amin F, Jain J, Tanwar S. Study of Convolvulus pluricaulis for antioxidant and anticonvulsant activity. Cent Nerv Syst Agents Med Chem. 2012;12:55-9.

41. Dhar A, Maurya SK, Mishra A, Singh GK, Singh MK, Seth A. Preliminary screening of a classical ayurvedic formulation for anticonvulsant activity. Anc Sci Life. 2016;36:28-34

42. Selkoe DJ. Cell biology of protein misfolding: The examples of Alzheimer's and Parkinson's diseases. Nat Cell Biol. 2004;6:1054-61.

43. Parfitt GM, Campos RC, Barbosa AK, Koth AP, Barros DM. Participation of hippocampal cholinergic system in memory persistence for inhibitory avoidance in rats. Neurobiol Learn Mem. 2012;97:183-8.

\section{GRAPHICAL ABSTRACT}

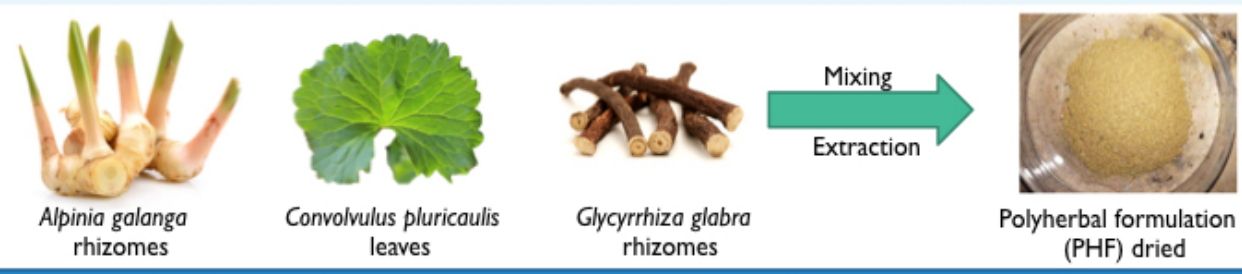

PHF SUSPENSION SCOPOLAMINE INDUCED MEMORY LOSS EXPERIMENTAL ANIMAL MODELS

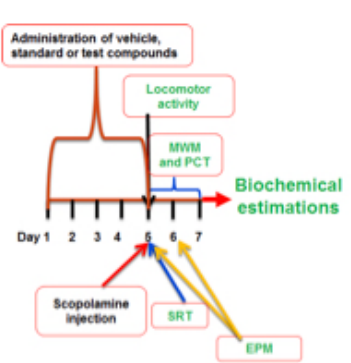

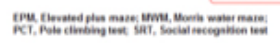
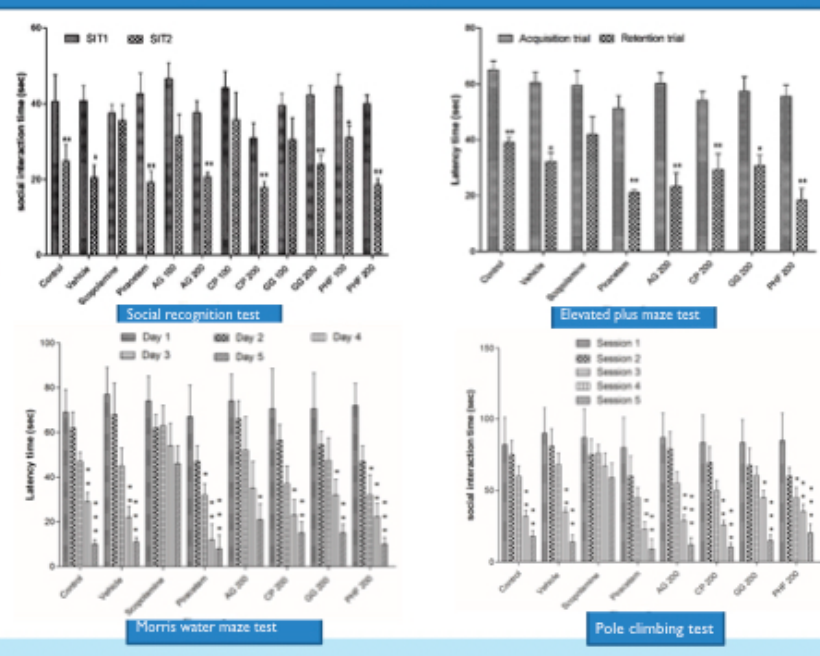


\section{ABOUT AUTHORS}

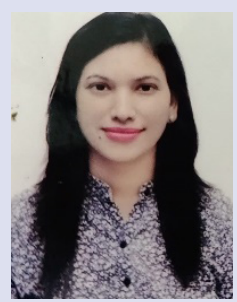

Deepa Shukla is Ph D scholar in Amity Institute of Pharmacy, Amity University Uttar Pradesh, Lucknow Campus, India. She completed her B Pharm and M Pharm from Dr. A.P.J. Abdul Kalam Technical University, Uttar Pradesh. She has been teaching and researching for more than 6 years.
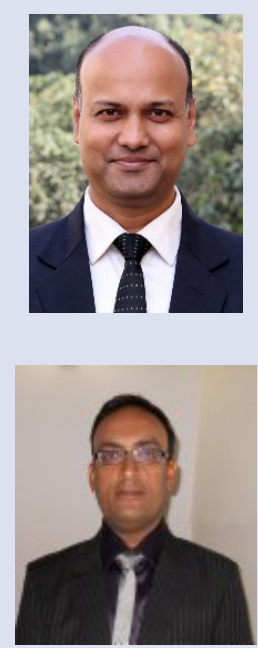

Dr. Sajal Srivastava is currently working as a Dy Director \& Associate professor at the Department of Pharmaceutical Chemistry, Amity Institute of Pharmacy, Amity University Uttar Pradesh, Lucknow Campus, India. He is Head of Department of Pharmaceutical Chemistry. He has over 17 years of experience in teaching Phytochemistry, Medicinal Chemistry and Instrumental Techniques. Dr. Srivastava's main research area is medicinal plants and chemistry of heterocyclic compound. He has also acquired expertise in the development of nasal dosage form. He has authored many book chapters and research articles in peer reviewed journals. In his research area many post-graduate scholars are pursuing their master and doctoral degree.

Talha Jawaid is an Assistant Professor of Pharmacology college of Medicine at AL-IMAM BIN SAUD ISLAMIC UNIVERSITY, Riyadh, Kingdom of Saudi Arabia. He graduated from Rajiv Gandhi University of health sciences, Bangalore and finished his PhD from Integral University, Lucknow. He Participated in teaching Pharmacology to all medical professional school students. He has 15 years of teaching and research experience. Dr. Talha Jawaid main research area is neuropharmacology and cardiovascular pharmacology. He has published various research paper in peer review journals. He has published one book in his credit.

Cite this article: Shukla D, Srivastava S, Jawaid T. Memory Enhancing Efficacy of an Ayurvedic Polyherbal Formulation on Scopolamine-Induced Memory Deficit Experimental Models.Pharmacog J. 2020;12(3):589-97. 